\title{
Methylomic markers of persistent childhood asthma: a longitudinal study of asthma-discordant monozygotic twins
}

Therese M. Murphy ${ }^{1 *}$, Chloe C. Y. Wong ${ }^{2}$, Louise Arseneault ${ }^{2}$, Joe Burrage ${ }^{1}$, Ruby Macdonald ${ }^{1}$, Eilis Hannon ${ }^{1}$, Helen L. Fisher ${ }^{2}$, Antony Ambler ${ }^{2}$, Terrie E. Moffitt ${ }^{2,3,4}$, Avshalom Caspi ${ }^{2,3,4}$ and Jonathan Mill ${ }^{1,2}$

\begin{abstract}
Background: Asthma is the most common chronic inflammatory disorder in children. The aetiology of asthma pathology is complex and highly heterogeneous, involving the interplay between genetic and environmental risk factors that is hypothesized to involve epigenetic processes. Our aim was to explore whether methylomic variation in early childhood is associated with discordance for asthma symptoms within monozygotic (MZ) twin pairs recruited from the Environmental Risk (E-Risk) longitudinal twin study. We also aimed to identify differences in DNA methylation that are associated with asthma that develops in childhood and persists into early adulthood as these may represent useful prognostic biomarkers.
\end{abstract}

Results: We examined genome-wide patterns of DNA methylation in buccal cell samples collected from $37 \mathrm{MZ}$ twin pairs discordant for asthma at age 10. DNA methylation at individual $\mathrm{CpG}$ sites demonstrated significant variability within discordant MZ twin pairs with the top-ranked nominally significant differentially methylated position (DMP) located in the HGSNAT gene. We stratified our analysis by assessing DNA methylation differences in a sub-group of MZ twin pairs who remained persistently discordant for asthma at age 18. The top-ranked nominally significant DMP associated with persisting asthma is located in the vicinity of the HLX gene, which has been previously implicated in childhood asthma.

Conclusions: We identified DNA methylation differences associated with childhood asthma in peripheral DNA samples from discordant MZ twin pairs. Our data suggest that differences in DNA methylation associated with childhood asthma which persists into early adulthood are distinct from those associated with asthma which remits.

Keywords: Asthma, DNA methylation, Epigenetics, Monozygotic twins

\section{Background}

Asthma is a common, complex and highly heterogeneous disorder characterized by recurring episodes of breathlessness and wheezing [1]. Asthma affects approximately 235 million people worldwide and is the most prevalent chronic inflammatory disorder in children [2]. The natural history of childhood-onset asthma is complex; it is commonly characterized by periods of remission and relapse [3, 4]. The heterogeneous features of asthma may indicate subtypes of the disease with distinct molecular pathology [5, 6], and recent analyses suggest that remitting and persistent

\footnotetext{
* Correspondence: t.murphy@exeter.ac.uk

'University of Exeter Medical School, University of Exeter, Exeter, UK Full list of author information is available at the end of the article
}

childhood-onset asthma is aetiologically distinct [7]. Currently, the diagnosis of asthma relies heavily on clinical features [1]. Understanding the molecular mechanisms involved in the onset and stability of asthma will facilitate the identification of children at increased risk of developing severe and persistent asthma in the future.

Asthma is known to involve complex interplay between genetic and environmental risk factors. Twin studies have demonstrated that the aetiology of asthma has a significant genetic contribution, with heritability estimates ranging from 35 to $80 \%$ [8-10]. Genome-wide association studies (GWAS) have identified a small number of common risk variants robustly associated with asthma, including a gene-rich locus on chromosome 
17q21 specific to childhood-onset disease [11]. Identified variants, however, account for only a small proportion of the estimated heritability $[1,11,12]$. Epidemiological research also highlights associations between specific environmental exposures (including tobacco smoke $[4,13]$ and microbial and viral agents $[14,15])$ and the onset of asthma, with exposures at certain critical periods during early childhood being particularly important [1]. Recent studies have started to examine the role of epigenetic processes-acting to developmentally regulate gene expression via modifications to DNA, histone proteins and chromatin-in complex disease phenotypes [16] including asthma. A number of studies have identified locusspecific variation in DNA methylation associated with asthma pathogenesis [17-20]. One study linked differential DNA methylation in the vicinity of two candidate genes (FOXP3 and IFNY) with asthma in a study of $N=$ 21 asthma-discordant adult monozygotic (MZ) twin pairs [18]. A recent longitudinal study observed asthmarelated changes in DNA methylation at specific genetic loci including IL4 and IL4R [17]. However, such published research examining epigenetic variation in asthma has primarily focused on candidate immune-related genes; few studies have taken a genome-wide approach [21]. Of note, a recent epigenome-wide methylation study (EWAS) identified significant DNA methylation changes at several loci associated with imunnunoglobulin E (IgE) levels, which are known to correlate positively with allergic diseases such as asthma [22]. However, most patient samples have been cross-sectional and thus it is unknown whether prior findings of methylomic differences are differentially associated with persistent or remitting asthma in early childhood.

The aim of the current study was to explore whether methylomic variation in early childhood is associated with discordance for asthma in 37 pairs of MZ twins. We were interested in identifying differences in DNA methylation that are associated with asthma that develops in childhood and persists into early adulthood as these may represent useful prognostic biomarkers. The use of disease-discordant MZ twins represents a powerful strategy in epigenetic epidemiology because identical twins are matched for genotype, age, sex, maternal environment, population cohort effects and exposure to many shared environmental factors during childhood [23]. We profiled DNA obtained from buccal swabs, which have previously been used as a surrogate for airway epithelial cells in DNA methylation studies [19].

\section{Results}

Brief overview of experimental approach

An overview of the methodological approach used in this study is given in Additional file 1: Figure S1. Briefly, we assessed genome-wide patterns of DNA methylation in asthma-discordant $\mathrm{MZ}$ twins and concordant unaffected MZ twins at age 10 using the Illumina $450 \mathrm{~K}$ HumanMethylation microarray (450K array). Pre-processing, normalization and stringent quality control were performed as previously described [24] (see Methods for specific details). Our analyses focused on identifying differentially methylated positions (DMPs) associated with asthma in (i) all asthma-discordant MZ twins at age 10 (Additional file 1: Figure S1A) and (ii) a sub-group with persistent asthma who were discordant for asthma at age 10 and also at age 18 (Additional file 1: Figure S1B). Using DNA previously collected at age 5 , we subsequently assessed longitudinal changes in DNA methylation (between ages 5 and 10) in persistent-asthmadiscordant MZ twins (Additional file 1: Figure S1C). Finally, we examined epigenetic variation at topranked persistent-asthma-associated DMPs in (i) an asthma-remission group, comprising of $\mathrm{MZ}$ twin pairs discordant for asthma at age 10 but concordant for no asthma phenotype at 18 , and (ii) concordant unaffected MZ twin pairs where neither twin had asthma at both ages 10 and 18 (Additional file 1: Figure S1D).

\section{Differentially methylated positions at age 10 associated with childhood asthma}

Our primary focus was on within-pair DNA methylation differences detected at age 10, as an accurate diagnosis of asthma before age 5 is difficult $[25,26]$. As expected, within-twin patterns of DNA methylation were highly correlated across all $37 \mathrm{MZ}$ pairs (mean within-twin $r$ for DNA methylation across all $450 \mathrm{~K}$ array probes $=0.97$ ) and no difference in overall mean DNA methylation (calculated by averaging across all probes on the $450 \mathrm{~K}$ array) was observed between affected and unaffected twins $(P=0.81)$, indicating that childhood asthma is not associated with any global changes in DNA methylation. In contrast, DNA methylation at individual $\mathrm{CpG}$ sites demonstrated significant variability within discordant $\mathrm{MZ}$ twin pairs. Table 1 lists the top-ranked nominally significant DMPs associated with asthma at age 10 (listing all with a nominal $\left.P<1 \times 10^{-4}\right)$. Although no DMP remained significant after Bonferroni multiple test correction, permutation analyses of the top-ranked loci revealed significant empirical $P$ values. Consistent within-twin differences in DNA methylation were observed across the majority of discordant MZ twin pairs $(n=37)$ for these top-ranked DMPs (Fig. 1). The top-ranked DMP, cg03284554, located in the promoter region of the heparan- $\alpha$-glucosaminide $\mathrm{N}$-acetyltransferase (HGSNAT) gene on chromosome $8 \mathrm{q} 21$, was consistently hypermethylated in asthmaaffected twins compared to their unaffected co-twin 
Table 1 The top-ranked DMPs in asthma-discordant MZ twins

\begin{tabular}{|c|c|c|c|c|c|c|c|c|c|c|c|}
\hline Probe ID & $\begin{array}{l}\text { Co-twin } \\
\text { mean }\end{array}$ & $\begin{array}{l}\text { Asthma } \\
\text { mean }\end{array}$ & Mean $\Delta \beta$ & $P$ value & $\begin{array}{l}\text { Empirical } \\
P \text { value }\end{array}$ & Hg19 & $\begin{array}{l}\text { Relation to } \mathrm{CpG} \\
\text { island }\end{array}$ & $\begin{array}{l}\text { Gene region feature } \\
\text { category (UCSC) }\end{array}$ & $\begin{array}{l}\text { Illumina gene } \\
\text { annotation }\end{array}$ & $\begin{array}{l}\text { Probe } \\
\text { type }\end{array}$ & $\begin{array}{l}\text { Gene annotation from GREAT } \\
\text { (distance from TSS) }\end{array}$ \\
\hline cg03284554 & 0.178 & 0.218 & 0.041 & $6.87 \mathrm{E}-06$ & $<0.0001$ & Chr8:43113670 & N_Shore & TSS1500 & HGSNAT & $\|$ & HGSNAT (-1078) \\
\hline cg01496463 & 0.761 & 0.795 & 0.034 & $1.80 \mathrm{E}-05$ & 0.0002 & Chr12:3262908 & & 3'UTR & TSPAN9 & $\|$ & $\begin{array}{l}\text { PRMT8 (-207777), TSPAN9 } \\
(+206127)\end{array}$ \\
\hline cg04373937 & 0.836 & 0.859 & 0.023 & 4.26E-05 & $<0.0001$ & Chr14:29622576 & & Intergenic & & $\|$ & G2E3 (-475503), PRKD1 (-155927) \\
\hline cg14688104 & 0.035 & 0.038 & 0.003 & 4.29E-05 & 0.0001 & Chr8:99508617 & Island & 1stExon; 5'UTR & KCNS2 & 1 & KCNS2 (+192) \\
\hline cg08158233 & 0.244 & 0.192 & -0.052 & 5.36E-05 & 0.0001 & Chr8:37470214 & & Intergenic & & $\|$ & $\begin{array}{l}\text { ZNF703 (-202244), KCNU1 } \\
(+709215)\end{array}$ \\
\hline cg17269596 & 0.581 & 0.637 & 0.056 & 5.49E-05 & 0.0004 & Chr1:243061735 & N_Shelf & Intergenic & & $\|$ & FAM36A (-3526) \\
\hline cg14299157 & 0.813 & 0.756 & -0.058 & 5.59E-05 & $<0.0001$ & Chr9:137272770 & N_Shelf & Intergenic & & $\|$ & $\begin{array}{l}\text { PPP1R26 (-238698), OLFM1 } \\
(+165861)\end{array}$ \\
\hline cg21201551 & 0.747 & 0.779 & 0.032 & 5.90E-05 & 0.0001 & Chr1:31404820 & S_Shelf & Intergenic & & $\|$ & PUM1 (-93670), NKAIN1 (+80500) \\
\hline cg16414472 & 0.503 & 0.414 & -0.089 & $6.05 \mathrm{E}-05$ & 0.0002 & Chr11:67866681 & & Body & LRP5 & । & PPP6R3 (-118080), LRP5 (+29998) \\
\hline cg01431063 & 0.057 & 0.072 & 0.014 & $8.92 \mathrm{E}-05$ & $<0.0001$ & Chr10:115850893 & Island & Intergenic & & $\|$ & TDRD1 (-78125), ADRB1 (+57098) \\
\hline cg01048931 & 0.071 & 0.084 & 0.013 & $9.42 \mathrm{E}-05$ & $<0.0001$ & Chr7:55639931 & Island & Body & VOPP1 & । & VOPP1 (+268) \\
\hline
\end{tabular}

Ranked by $P$ value. Empirical $P$ value $=$ (number of permutations which are at least as significant as the true result $(P<0.0001)$ divided by the number of permutations performed $(n=10000)$ )

DMPs differentially methylated positions, MZ monozygotic, GREAT Genomic Regions Enrichment of Annotations Tool, TSS transcription start site, UCSC University of California Santa Cruz genome browser 


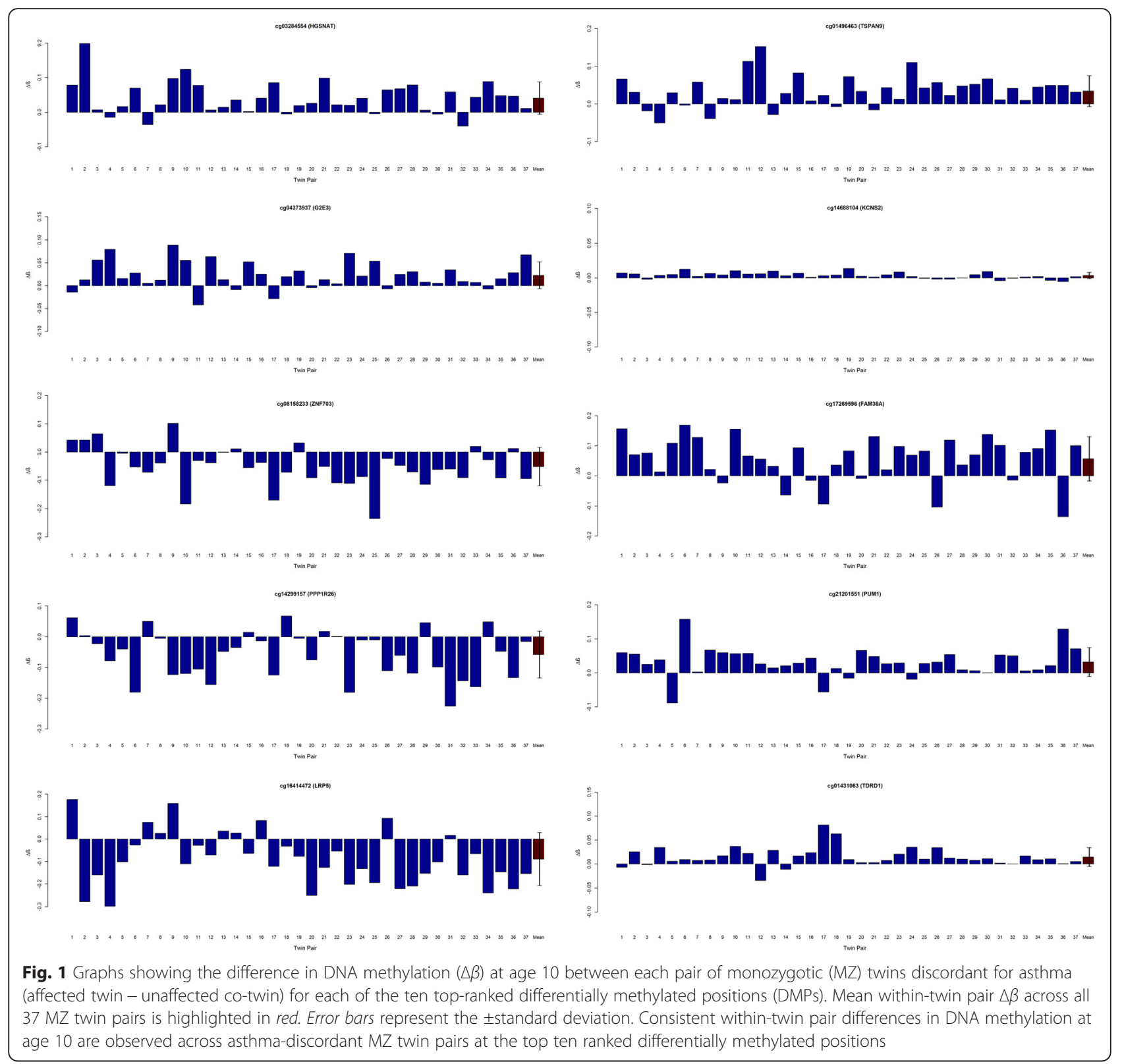

(mean $\Delta \beta=0.041, P=6.87 \mathrm{E}-06$, permuted empirical $P<0.0001)$. Of note, HGSNAT gene expression is down-regulated in paediatric allergic asthma cases compared to controls [27]. Gene ontology (GO) term enrichment analysis of the age-10 DMPs (see Additional file 2: Table S1 for a list of included loci) identified 199 nominally significantly enriched terms (see Additional file 2: Table S2), including categories related to anion/ion transportation, regulation of ion transport (GO:0043269 ( $P=$ 0.0008), GO:0006811 $(P=0.003))$ and regulation of anion transport (GO:0044070 $(P=0.0026))$. Interestingly, changes in ion transport have previously been implicated in asthma pathogenesis [28].
Methylomic profiling of MZ twins in a persistent-asthma sub-group

Childhood asthma regularly remits in adolescence and early adulthood [3, 4], with remitting and persistent childhood asthma potentially having differing aetiology [7]. We therefore stratified our analysis by assessing age-10 DNA methylation differences in a sub-group of $\mathrm{MZ}$ twin pairs ( $n=13$ pairs) who remained persistently discordant for asthma at age 18. Table 2 and Fig. 2 show the top-ranked age-10 DMPs associated with asthma that persisted to age 18 , which may represent useful childhood biomarkers of prognosis. Again, no DMP remained significant after Bonferroni correction, but empirical $P$ values generated 
Table 2 The top-ranked DMPs in age-10 MZ twins persistently discordant for asthma

\begin{tabular}{|c|c|c|c|c|c|c|c|c|c|c|c|c|c|}
\hline \multirow[b]{2}{*}{ Probe ID } & \multicolumn{5}{|l|}{ Age 10} & \multicolumn{2}{|l|}{ Age 5} & \multirow[b]{2}{*}{$\begin{array}{l}\text { Relation to } \\
\text { CpG island }\end{array}$} & \multirow[b]{2}{*}{$\begin{array}{l}\text { Gene region feature } \\
\text { category (UCSC) }\end{array}$} & \multirow[b]{2}{*}{$\mathrm{Hg} 19$} & \multirow[b]{2}{*}{$\begin{array}{l}\text { Illumina gene } \\
\text { annotation }\end{array}$} & \multirow[b]{2}{*}{$\begin{array}{l}\text { Probe } \\
\text { type }\end{array}$} & \multirow[b]{2}{*}{$\begin{array}{l}\text { Gene annotation from GREAT } \\
\text { (distance from TSS) }\end{array}$} \\
\hline & $\begin{array}{l}\text { Co-twin } \\
\text { mean }\end{array}$ & $\begin{array}{l}\text { Asthma } \\
\text { mean }\end{array}$ & Mean $\Delta \beta$ & $P$ value & $\begin{array}{l}\text { Empirical } \\
P \text { value }\end{array}$ & Mean $\Delta \beta$ & $P$ value & & & & & & \\
\hline cg23603194 & 0.289 & 0.180 & -0.109 & 6.87E-06 & 0.0009 & 0.056 & 0.0519 & N_Shore & Intergenic & Chr1:221060753 & & $\|$ & $\begin{array}{l}\text { HLX (+8011), DUSP10 } \\
(+854762)\end{array}$ \\
\hline cg27385757 & 0.353 & 0.286 & -0.067 & $2.16 \mathrm{E}-05$ & 0.0012 & 0.029 & 0.1966 & S_Shore & TSS1500; 3'UTR & Chr6:30656024 & $\begin{array}{l}\text { KIAA1949; } \\
\text { NRM }\end{array}$ & $\|$ & PPP1R18 (-932) \\
\hline cg06483698 & 0.805 & 0.848 & 0.043 & $2.64 \mathrm{E}-05$ & 0.0007 & -0.006 & 0.6847 & N_Shore & Body & Chr7:6310290 & CYTH3 & $\|$ & $\begin{array}{l}\text { CYTH3 (+1951), USP42 } \\
(+165741)\end{array}$ \\
\hline cg05895618 & 0.559 & 0.655 & 0.096 & $2.69 \mathrm{E}-05$ & 0.0007 & -0.026 & 0.5367 & & $5^{\prime} U T R$ & Chr11:19222395 & CSRP3 & $\|$ & $\begin{array}{l}\text { CSRP3 (+1193), ZDHHC13 } \\
(+83704)\end{array}$ \\
\hline cg14868530 & 0.081 & 0.098 & 0.017 & $3.36 \mathrm{E}-05$ & 0.0005 & -0.008 & 0.0351 & Island & 5'UTR; 1stExon & Chr15:73976679 & CD276 & । & CD276 (+58) \\
\hline cg21304454 & 0.530 & 0.392 & -0.138 & 3.59E-05 & 0.0009 & 0.070 & 0.1223 & N_Shelf & Body & Chr1:17302859 & MFAP2 & $\|$ & $\begin{array}{l}\text { MFAP2 (+4313), CROCC } \\
(+54415)\end{array}$ \\
\hline cg11998205 & 0.853 & 0.806 & -0.047 & $4.28 \mathrm{E}-05$ & 0.0017 & -0.033 & 0.0361 & S_Shelf & Body & Chr19:48840527 & TMEM143 & । & $\begin{array}{l}\text { EMP3 (+11899), TMEM143 } \\
(+26658)\end{array}$ \\
\hline cg18513344 & 0.210 & 0.137 & -0.072 & 4.39E-05 & 0.0007 & -0.022 & 0.3459 & & Body & Chr3:195531298 & MUC4 & $\|$ & $\begin{array}{l}\text { MUC4 (+7545), MUC20 } \\
(+83546)\end{array}$ \\
\hline cg08657206 & 0.256 & 0.221 & -0.035 & $5.55 \mathrm{E}-05$ & 0.0009 & -0.005 & 0.7971 & N_Shore & Intergenic & Chr1:180197901 & & । & LHX4 (-1531) \\
\hline cg19865472 & 0.897 & 0.844 & -0.052 & $5.90 \mathrm{E}-05$ & 0.0004 & -0.065 & 0.1373 & Island & $3^{\prime} U T R$ & Chr19:617133 & $\mathrm{HCN} 2$ & । & $\begin{array}{l}\text { POLRMT (+16434), HCN2 } \\
(+27241)\end{array}$ \\
\hline cg26280666 & 0.0976 & 0.0717 & -0.0259 & $6.13 \mathrm{E}-05$ & 0.0009 & -0.0115 & 0.4006 & N_Shore & Body & Chr8:72755568 & MSC & $\|$ & EYA1 (-486590), MSC (+1162) \\
\hline cg13512987 & 0.5252 & 0.6452 & 0.1200 & $6.77 \mathrm{E}-05$ & 0.0005 & -0.0438 & 0.1137 & & 5'UTR; 1stExon & Chr12:6898785 & CD4 & $\|$ & CD4 (+148) \\
\hline $\operatorname{cg} 24664347$ & 0.7364 & 0.8161 & 0.0797 & $7.51 \mathrm{E}-05$ & 0.0006 & -0.0624 & 0.0007 & S_Shore & TSS1500 & Chr8:86841010 & REXO1L2P & $\|$ & $\begin{array}{l}\text { REXO1L1 (-51705), PSKH2 } \\
(+240840)\end{array}$ \\
\hline $\operatorname{cg} 25346117$ & 0.6694 & 0.7450 & 0.0756 & $8.06 \mathrm{E}-05$ & 0.0004 & 0.0030 & 0.8688 & & Body & Chr1:116923256 & ATP1A1 & $\|$ & $\begin{array}{l}\text { ATP1A1 (+7462), CD58 } \\
(+190458)\end{array}$ \\
\hline cg09587549 & 0.2320 & 0.2647 & 0.0327 & $9.75 \mathrm{E}-05$ & 0.0005 & -0.0006 & 0.9742 & Island & 5'UTR; 1stExon & Chr16:31214126 & PYCARD & । & $\operatorname{PYCARD}(-30)$ \\
\hline cg03225548 & 0.7651 & 0.6807 & -0.0844 & $9.90 \mathrm{E}-05$ & 0.0004 & -0.0014 & 0.9638 & N_Shelf & Body; 5'UTR & Chr18:71811234 & FBXO15 & $\|$ & $\begin{array}{l}\text { TIMM21 (-4511), FBXO15 } \\
(+3865)\end{array}$ \\
\hline cg17130754 & 0.7563 & 0.6967 & -0.0597 & 9.99E-05 & 0.0004 & 0.0478 & 0.0739 & & Intergenic & Chr10:3536341 & & $\|$ & $\begin{array}{l}\text { PITRM1 (-321309), KLF6 } \\
(+291131)\end{array}$ \\
\hline
\end{tabular}

Ranked by $P$ value. Empirical $P$ value $=$ (number of permutations which are at least as significant as the true result $(P<0.0001)$ divided by the number of permutations performed $(n=8192)$ )

DMPs differentially methylated positions, MZ monozygotic, GREAT Genomic Regions Enrichment of Annotations Tool, TSS transcription start site, UCSC University of California Santa Cruz genome browser 


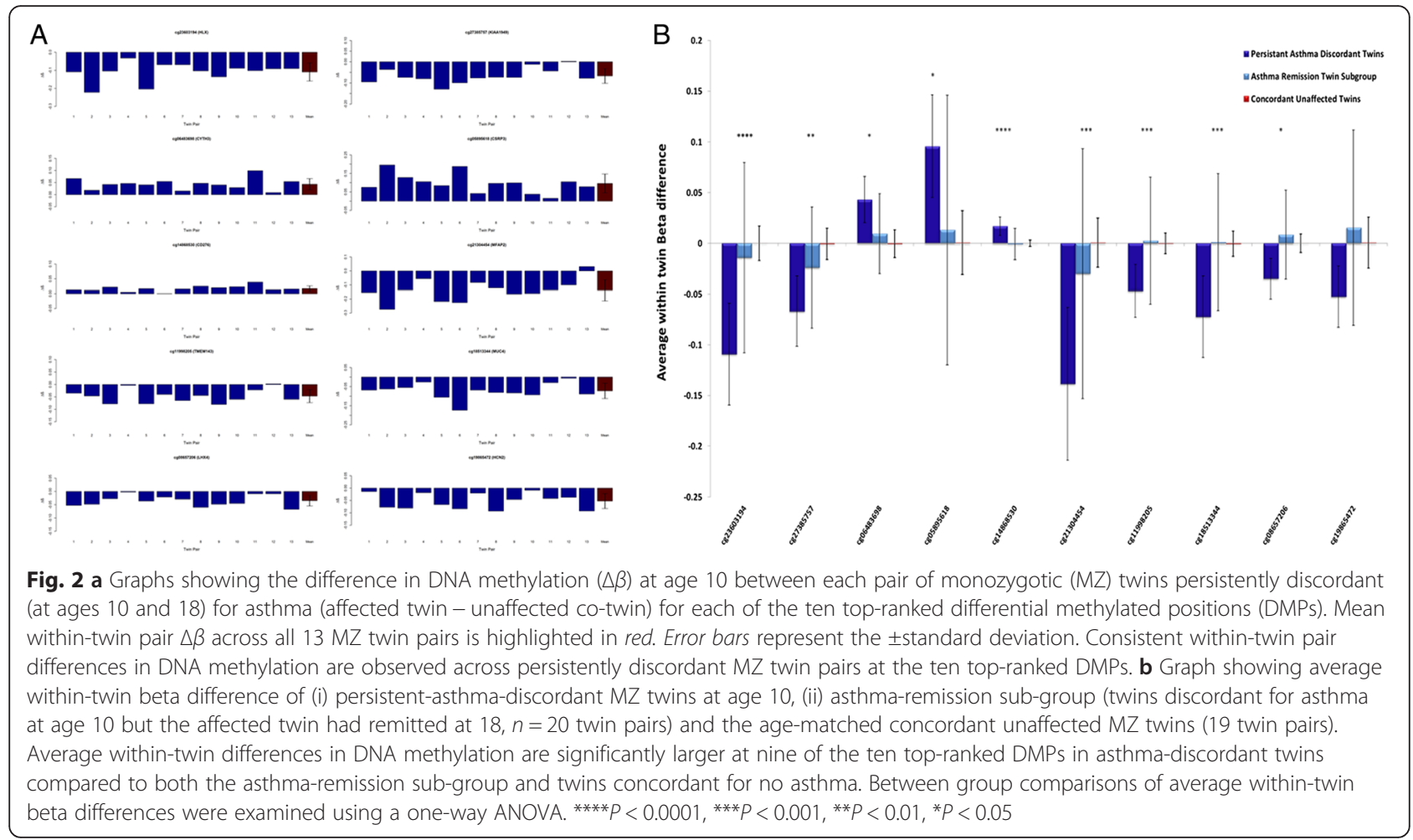

from permutation analyses suggest that these represent significant differences. The top-ranked DMP associated with persisting asthma (cg23603194, located downstream of the $H L X$ gene) was consistently hypomethylated in asthma-affected twins compared with their unaffected cotwin (mean $\Delta \beta=-0.11, P=6.87 \mathrm{E}-06$, permuted empirical $P=0.0009$ ). Interestingly, a number of additional probes (cg18788664, cg10975889, cg15730491) annotated to the $H L X$ gene region were also differentially methylated in twins discordant for persistent asthma compared to their unaffected co-twin (see Fig. 3). Of note, genetic variation in this gene has been previously associated with the development of childhood asthma $[29,30]$ and cytokine secretion at birth [31]. We next tested the specificity of our persistent-asthma-associated DMPs, by comparing average within-twin DNA methylation differences at these loci in (i) an asthma-remission group, comprising of MZ twin pairs discordant for asthma at age 10 but concordant for

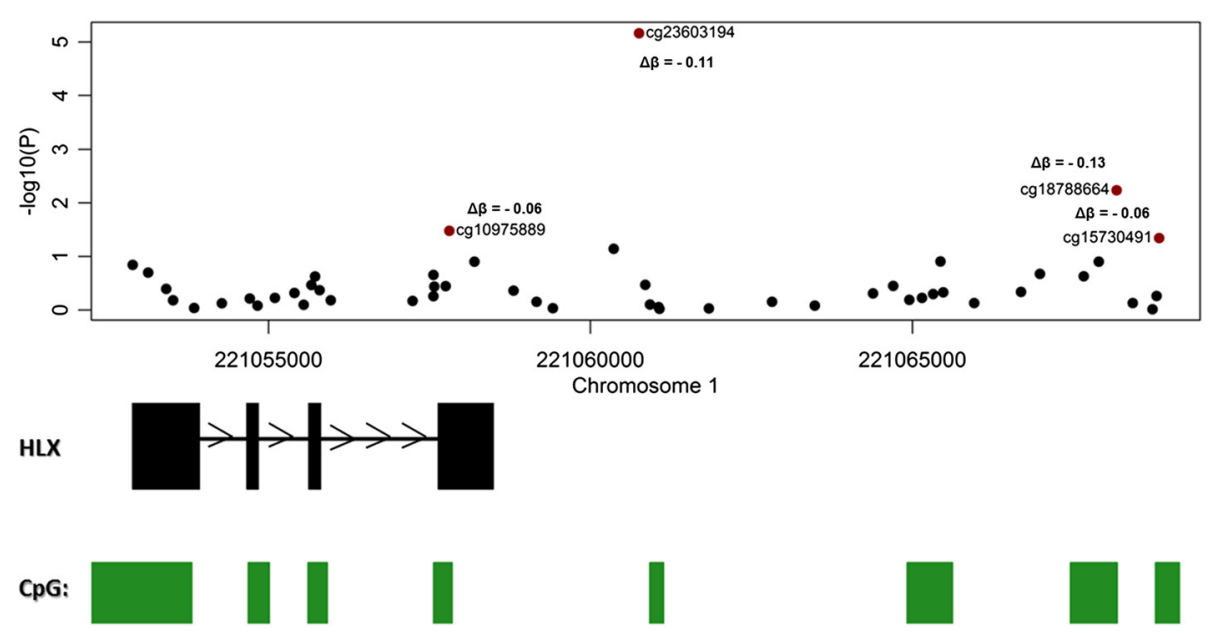

Fig. 3 A number of probes annotated to the HLX gene were significantly differentially methylated in persistent-asthma twins compared to their unaffected co-twin. Asthma-associated differentially methylated positions are highlighted in red. Green bars denote the location of annotated CpG islands. Of note, asthma-associated DMPs overlap known CpG islands downstream of the HLX gene. $\triangle \beta=$ mean within-twin beta difference 
no asthma phenotype at 18 ( $n=20$ twin pairs), and (ii) concordant unaffected MZ twin pairs where neither twin had asthma at both ages 10 and 18 ( $n=19$ twin pairs). At nine of the ten top-ranked DMPs, average within-twin differences in DNA methylation were significantly different between groups (see Fig. 2b), with post hoc pairwise comparisons indicating that average within-twin differences in DNA methylation are significantly larger at these top-ranked DMPs in the persistent-asthma-discordant twins compared to both the asthma-remission twin subgroup and twins concordant for no asthma. GO term enrichment analysis was undertaken on persistent age-10 asthma DMPs (nominal $P<0.001$, see Additional file 2: Table S3 for a list of loci included in the analysis). We identified 142 enriched (nominal $P<0.05$ ) terms (see Additional file 2: Table S4), including categories related to interleukin-2 (IL-2) processes (GO:0042094 $(P=0.0009)$, GO:0032623 $(P=0.0025))$ and type I interferon production (GO:0032480 $(P=0.0039))$. Of note, both IL-2 and interferon pathways play an important role in cellmediated immunity $[32,33]$ and have previously been implicated in asthma pathogenesis [34, 35].

\section{Longitudinal DNA methylation changes in persistent- asthma $\mathrm{MZ}$ twins}

DNA methylation at the top-ranked age-10 persistentasthma DMPs $(P<0.0001)$ could be examined in matched buccal cell DNA collected at age 5 for 11 of the 13 persistently discordant MZ twin pairs (2 pairs lacked age-5 DNA methylation data). Although two of the topranked probes (cg14868530 (annotated to CD276) and cg11998205 (annotated to TMEM143)) were significantly differentially methylated in the same direction between affected twins and their unaffected co-twin at age $5(P=0.035$ and $P=0.036$, respectively), no significant differences at age 5 were observed for the other topranked loci, and there was no overall correlation in within-twin differences at ages 5 and 10 for the topranked persistent-asthma DMPs. These findings suggest that epigenetic variation associated with asthma persisting through adolescence is not detectable in very early childhood. Within our persistent-asthma sub-group, we therefore next examined persistent-asthma-associated intra-individual changes in DNA methylation between ages 5 and 10. For each probe, we calculated the change in DNA methylation from age 5 to age 10 (longitudinal $\Delta \beta$ ) for each individual and examined the difference in longitudinal $\Delta \beta$ between affected twins and their unaffected co-twin. The top-ranked probe (cg26090469), located in AFF4, became significantly hypomethylated from age 5 to age 10 in twins who developed persistent asthma, compared to their unaffected co-twin $(P=$ 1.41E-06, Table 3). GO term enrichment analysis was performed for the genes associated with the asthma- associated (nominal $P<0.001$ ) intra-individual changes in DNA methylation identified between ages 5 and 10 (see Additional file 2: Table S5 for a list of genes included). This analysis identified 90 enriched (nominal $P<0.05$ ) terms (see Additional file 2: Table S6), with the top-ranked categories being related to activin receptor signalling (GO:0032926 $(P=0.0006)$, GO:0032925 $(P=$ $0.005))$ and epithelium development (GO:0060429 $(P=$ $0.0006)$ ).

\section{Discussion}

In this study, we first assessed genome-wide patterns of DNA methylation in buccal cell samples collected from 37 asthma-discordant MZ twin pairs at age 10. We identified a number of asthma-associated DMPs, characterized by consistent within-pair differences in DNA methylation. The top-ranked DMP (cg03284554) is located upstream of HGSNAT, which has been previously shown to be down-regulated in paediatric allergic asthma [27]. We next stratified our analysis by assessing DNA methylation differences in a sub-group of MZ twin pairs who remained persistently discordant for asthma 8 years later, at age 18. The top-ranked DMP associated with persisting asthma (cg23603194) is located $8 \mathrm{~kb}$ downstream of the transcriptional start site (TSS) of the $H L X$ gene, which has been previously implicated in childhood asthma [29, 30]. Moreover, a number of additional probes (cg18788664, cg10975889, cg15730491) located in the proximity of the $H L X$ gene were significantly differentially methylated in affected twins compared to their unaffected co-twin. Although the majority of these probes are located $>8 \mathrm{~kb}$ downstream of the $H L X$ TSS, their proximity to annotated CpG islands (see Fig. 3) suggests that they reside in potential regulatory regions. $H L X$ has been identified as an important regulator of $\mathrm{TH}_{1}$ differentiation and a suppressor of $\mathrm{TH}_{2}$ commitment, mediating pathways that are known to be perturbed in asthma [29, 36]. The functional relevance of DNA methylation changes downstream of the $H L X$ gene warrants further investigation.

Several other DMPs identified in the persistent-asthma sub-group analysis are located in the vicinity of genes that have previously been implicated in asthma. For example, cg13512987, located in the first exon of the cluster of differentiation 4 (CD4) gene, was significantly hypermethylated in asthma-affected twins compared to their unaffected cotwin. CD4 is a glycoprotein found on the surface of immune cells such as $\mathrm{T}$ helper cells, monocytes, macrophages and dendritic cells [37]. CD4+ T cells are increased in broncho-alveolar lavage fluid and bronchial biopsy specimens from asthmatic patients [38]. Similarly, cg14868530, which is hypermethylated in affected twins compared to their unaffected co-twin, is located in the first exon of CD276, a gene important for $\mathrm{T}$ cell proliferation [39]. 
Table 3 The top-ranked CpG sites which show changes in DNA methylation levels overtime in the discordant MZ twins

\begin{tabular}{|c|c|c|c|c|c|c|c|c|c|c|}
\hline Probe ID & $\begin{array}{l}\text { Co-twin } \\
\text { mean }\end{array}$ & $\begin{array}{l}\text { Asthma } \\
\text { mean }\end{array}$ & $\begin{array}{l}\text { Mean } \\
\Delta \beta\end{array}$ & $P$ value & $\mathrm{Hg} 19$ & $\begin{array}{l}\text { Relation to } \\
\mathrm{CpG} \text { island }\end{array}$ & $\begin{array}{l}\text { Gene region } \\
\text { feature category } \\
\text { (UCSC) }\end{array}$ & $\begin{array}{l}\text { Illumina gene } \\
\text { annotation }\end{array}$ & $\begin{array}{l}\text { Probe } \\
\text { type }\end{array}$ & $\begin{array}{l}\text { Gene annotation } \\
\text { from GREAT } \\
\text { (distance from TSS) }\end{array}$ \\
\hline cg26090469 & -0.0122 & 0.0341 & 0.0463 & $1.41 \mathrm{E}-06$ & Chr5:132271449 & & Body & AFF4 & $\|$ & $\begin{array}{l}\text { AFF4 (+27904), } \\
\text { LEAP2 (+62092) }\end{array}$ \\
\hline cg02181624 & 0.1204 & -0.0649 & -0.1854 & $1.68 \mathrm{E}-06$ & Chr6:168716070 & N_Shelf & Body & DACT2 & $\|$ & $\begin{array}{l}\text { FRMD1 (-236232), } \\
\text { DACT2 (+4331) }\end{array}$ \\
\hline cg17199800 & -0.0902 & 0.0620 & 0.1522 & 9.47E-06 & Chr7:96632777 & N_Shore & Body & DLX6AS & $\|$ & DLX6 (-2512) \\
\hline cg21875946 & 0.0892 & -0.0276 & -0.1168 & $1.88 \mathrm{E}-05$ & Chr1:206663985 & & Body & IKBKE & $\|$ & $\begin{array}{l}\text { RASSF5 }(-16893) \text {, } \\
\text { IKBKE }(+20400)\end{array}$ \\
\hline cg15691003 & 0.0082 & -0.0205 & -0.0287 & 3.26E-05 & Chr1:22351864 & N_Shore & Body; TSS200 & HSPC157 & $\|$ & $\begin{array}{l}\text { CDC42 (-27255), } \\
\text { CELA3B (+48447) }\end{array}$ \\
\hline cg02836325 & -0.1285 & -0.0153 & 0.1132 & 3.37E-05 & Chr17:76403955 & & Body & PGS1 & $\|$ & $\begin{array}{l}\text { PGS1 (+29221), } \\
\text { DNAH17 (+169520) }\end{array}$ \\
\hline cg16789707 & -0.0958 & 0.0404 & 0.1362 & 4.33E-05 & Chr16:88767723 & S_Shelf & Body & RNF166 & $\|$ & $\begin{array}{l}\text { SNAI3 (-14842), } \\
\text { RNF166 (+5105) }\end{array}$ \\
\hline cg04313071 & 0.1063 & -0.0249 & -0.1312 & 4.33E-05 & Chr14:102685619 & & Body & WDR20 & $\|$ & $\begin{array}{l}\text { HSP90AA1 (-79534), } \\
\text { MOK (+85911) }\end{array}$ \\
\hline cg23847069 & 0.1153 & -0.0057 & -0.1210 & 4.79E-05 & Chr17:2702204 & & Body & RAP1GAP2 & I & $\begin{array}{l}\text { RAP1GAP2 (+2473), } \\
\text { OR1D5 (+264696) }\end{array}$ \\
\hline cg24293948 & 0.0646 & -0.0729 & -0.1375 & 5.04E-05 & Chr18:61670413 & S_Shore & Intergenic & & $\|$ & $\begin{array}{l}\text { SERPINB8 }(+33151) \\
\text { LINC00305 }(+95460)\end{array}$ \\
\hline cg06367321 & 0.1110 & -0.0015 & -0.1125 & 5.14E-05 & Chr16:30125232 & & $\begin{array}{l}\text { TSS200; } \\
\text { TSS1500 }\end{array}$ & $\begin{array}{l}\text { LOC100271831; } \\
\text { GDPD3 }\end{array}$ & । & GDPD3 (-355) \\
\hline cg06655665 & -0.1603 & -0.0359 & 0.1243 & 5.45E-05 & Chr2:38607629 & S_Shelf & Intergenic & & ॥ & ATL2 (-3198) \\
\hline cg25406011 & 0.1312 & -0.0175 & -0.1487 & $6.04 \mathrm{E}-05$ & Chr11:1254421 & Island & Body & MUC5B & $\|$ & $\begin{array}{l}\text { MUC5B }(+10127), \\
\text { TOLLIP }(+76470)\end{array}$ \\
\hline cg25494605 & 0.0873 & -0.0652 & -0.1525 & $6.55 \mathrm{E}-05$ & Chr5:173472097 & & TSS1500 & HMP19 & $\|$ & HMP19 (-626) \\
\hline cg24664347 & -0.1381 & 0.0087 & 0.1468 & $6.88 \mathrm{E}-05$ & Chr8:86841010 & S_Shore & TSS1500 & REXO1L2P & $\|$ & $\begin{array}{l}\text { REXO1L1 (-51705), } \\
\text { PSKH2 (+240840) }\end{array}$ \\
\hline cg18184910 & 0.2047 & 0.0402 & -0.1644 & 7.10E-05 & Chr6:47624247 & & TSS200 & GPR111 & $\|$ & GPR111 (-78) \\
\hline cg00840341 & 0.1094 & 0.0131 & -0.0963 & 7.60E-05 & Chr16:17609453 & & Intergenic & & $\|$ & $\begin{array}{l}\text { XYLT1 (-44716), } \\
\text { AK310228 (+825170) }\end{array}$ \\
\hline cg14141399 & 0.2139 & -0.0312 & -0.2451 & 7.66E-05 & Chr19:52228048 & & TSS1500 & HAS1 & $\|$ & HAS1 (-828) \\
\hline cg14179581 & -0.1193 & 0.0758 & 0.1951 & 7.74E-05 & Chr1:50881502 & Island & Intergenic & & $\|$ & $\begin{array}{l}\text { DMRTA2 (+7616), } \\
\text { ELAVL4 (+306909) }\end{array}$ \\
\hline cg21209859 & -0.0892 & 0.0351 & 0.1242 & $7.78 \mathrm{E}-05$ & Chr1:167682516 & N_Shore & Intergenic & & $\|$ & $\begin{array}{l}\text { CREG1 }(-159461), \\
\text { MPZL1 }(-8670)\end{array}$ \\
\hline cg21187770 & 0.1265 & -0.0432 & -0.1697 & 8.57E-05 & Chr2:26205876 & S_Shore & TSS1500 & KIF3C & I & KIF3C $(-434)$ \\
\hline cg01382502 & -0.1489 & -0.0279 & 0.1210 & 8.96E-05 & Chr16:22252504 & & Body & EEF2K & $\|$ & $\begin{array}{l}\text { POLR3E (-56236), } \\
\text { EEF2K (+34913) }\end{array}$ \\
\hline cg09900436 & -0.1813 & 0.0363 & 0.2175 & 8.96E-05 & Chr20:58630954 & & TSS200 & C20orf197 & $\|$ & $\mathrm{CDH} 26(+97484)$ \\
\hline cg16606561 & 0.2193 & 0.0631 & -0.1562 & $9.72 \mathrm{E}-05$ & Chr20:824641 & N_Shore & 5'UTR; TSS1500 & FAM110A & $\|$ & $\begin{array}{l}\text { FAM110A (+10286), } \\
\text { ANGPT4 (+72318) }\end{array}$ \\
\hline $\operatorname{cg} 15048437$ & 0.0067 & -0.0159 & -0.0226 & 9.85E-05 & Chr19:37019614 & Island & TSS1500 & ZNF260 & । & ZNF260 (-367) \\
\hline
\end{tabular}

\footnotetext{
Ranked by $P$ value

DMPs differentially methylated positions, MZ monozygotic, GREAT Genomic Regions Enrichment of Annotations Tool, TSS transcription start site, UCSC University of
} California Santa Cruz

Furthermore, cg18513344, which we found to be hypomethylated in affected twins, is associated with MUC4, a gene that encodes an airway mucin protein-a major constituent of mucus [40]. Interestingly, evaluation of airway biopsies from asthmatic patients have observed higher
MUC4 mRNA levels compared to normal healthy controls [41]. DNA methylation studies in other complex phenotypes report [42-44] similarly small absolute $(<10 \%)$ differences in DNA methylation to those observed in this study. The DNA methylation values reported in this study 
represent aggregate values across all cells from a given sample. A shift in DNA methylation of 5-10\% indicates that $\sim 5-10 \%$ of DNA molecules in the population assessed become fully methylated (or unmethylated) at that locus, with potentially large functional consequences in that specific cellular sub-population. Finally, GO analysis of differentially methylated loci associated with a persistent-asthma phenotype revealed an enrichment of immune-related pathways including IL-2 and interferon type I signalling pathways which have previously been implicated in asthma pathogenesis $[34,35]$. Together, our data suggest that epigenetic variation is associated with childhood asthma, and that methylomic differences may potentially be useful markers for predicting the persistence of asthma at age 18 .

A recent EWAS analysis identified robust DNA methylation changes at several loci associated with imunnunoglobulin E (IgE) levels, which are known to correlate positively with allergic diseases such as asthma [22]. Two of the 69 IgE-associated DMPs (cg11398517 $\quad(P=0.008)$, cg16522484 $(P=0.04))$ were nominally significantly associated with asthma in our primary asthmadiscordant cohort (37 twin pairs). Also, 5 of the 69 IgEassociated DMPs were nominally associated with asthma in our persistently discordant MZ twins (cg08404225 $(P=$ 0.003), $\operatorname{cg} 05215575(P=0.014), \operatorname{cg} 09676390 \quad(P=0.019)$, cg25494227 $(P=0.02), \operatorname{cg} 17749520 \quad(P=0.029))$. These DMPs were not associated with asthma in twin pairs where the affected twin had remission of symptoms by age 18 , although several IgE-associated DMPs were cg17890764 $(P=0.003), \quad \operatorname{cg} 07374928 \quad(P=0.01)$ and cg11398517 $(P=0.028)$; these DMPs may be associated with IgE levels in childhood asthma which remits in early adulthood. Although our findings require replication in larger independent prospective asthma cohorts, the data suggest that prognostic DNA methylation markers of persistent asthma may be identified. It would be interesting to combine epigenetic data with polygenic risk scores, which have previously been associated with life-course-persistent asthma [7].

DNA methylation at the top-ranked age-10 persistentasthma DMPs $(P<0.0001)$ was examined in matched buccal cell DNA collected at age 5 for 11 of the 13 persistently discordant MZ twin pairs. Although there was no overall correlation in within-twin differences at ages 5 and 10 for the top-ranked persistent-asthma DMPs, we identified a number of age-10 DMPs that were also nominally significantly differentially methylated in the twins at age 5 . These data suggest that DNA methylation of these loci could potentially represent early biomarkers for persistent asthma. We next examined asthmaassociated intra-individual changes in DNA methylation between ages 5 and 10. The top-ranked longitudinal DMP (cg26090469), which was significantly hypomethylated from age 5 to age 10 in twins with persistent asthma compared to their unaffected co-twin, is located in the AFF4 gene. Research suggests that AFF4, an important scaffold protein, may play a role in viral gene expression [45]. Similarly, cg25406011, located in exon 18 of the $M U C 5 B$ gene, was significantly hypomethylated from age 5 to age 10 in twins with persistent asthma compared to their unaffected co-twin. MUC5B codes for the major gel-forming mucin in mucus. Recently, it has been shown that mouse Muc5b is required for mucociliary clearance, for controlling infections in the airways and for immune homeostasis in mouse lungs [46]. Our data suggests that site-specific longitudinal intra-individual DNA methylation changes in $M U C 5 B$ may play a role in the pathogenesis and development of asthma. Genes annotated to the most DMPs between ages 5 and 10 in twins who develop persistent asthma highlighted significant GO term enrichment for activin receptor signalling and epithelium development. Notably, activin signalling has previously been implicated in airway remodelling in asthma [47].

Despite the power of the discordant MZ twin approach for epigenetic epidemiology, there are several limitations to this study. First, an event history calendar was used to record children's history of chronic health conditions at ages 5 and 10 and a set of seven asthma symptoms were assessed to determine asthma status at age 18. However, the questions used in this study are well established and have been validated and used previously in studies of asthma and other childhood phenotypes [48-51]. Second, our primary and secondary analyses utilized a small cohort of 74 twin children (37 MZ pairs) and 26 twin children (13 MZ twin pairs), respectively. Despite the modest sample size, the cases were exhaustive of asthma-discordant pairs in our birth cohort which has been shown to represent the UK population [52]. Nevertheless, our analyses were relatively underpowered to detect small changes in DNA methylation. Although no probe reaches Bonferroni-corrected levels of significance, DNA methylation studies in other complex phenotypes report similarly small absolute differences. Given the known non-independence of DNA methylation across the probes represented on the $450 \mathrm{~K}$ array [53], it is likely that conventional methods of global statistical significance (which assume statistical independence of the multiple tests) are not appropriate for these analyses [54]. As an alternative approach, we therefore report empirical $P$ values (generated by randomly re-assigning disease status and re-analysing the data) for each of the top-ranked probes using permutation testing [54]. After up to 10,000 permutations, each of our top-ranked probes was found to be significantly associated with asthma at an empirical $P<0.0009$. Third, methylomic analysis was performed on DNA from 
buccal cells, which may not represent the primary target tissue involved in asthma. However, buccal cells are an easily accessible tissue that encompasses a portion of the upper airway and have previously been proposed as a surrogate for airway epithelial cells [19]. Due to the limited availability of buccal cell DNA, technical validation, using bisulfite pyrosequencing, of our top-ranked DMPs was not performed in this study. Of note, however, we and others have previously validated small changes in DNA methylation identified from the $450 \mathrm{~K}$ array using pyrosequencing, highlighting the reliability of the $450 \mathrm{~K}$ array [43, 55-57]. Our analysis of asthma-concordant MZ twin pairs highlights the specificity of the differences we observed in disease-discordant twin pairs. Additionally, buccal cell RNA was not available for our MZ twin cohort and thus we were unable to directly examine the functional relevancy of asthma-associated DMPs on gene expression. One final caveat in this study is that chorionicity data were not available on these twins, a potential limitation given that whether or not MZ twins share a placenta may influence epigenomic and transcriptional differences mediated by subtle differences in the prenatal environment [58].

\section{Conclusions}

In summary, we have identified DNA methylation differences associated with childhood asthma in peripheral DNA samples from discordant MZ twin pairs. The topranked persistent-asthma-associated DMP (cg23603194) identified in this study is downstream of the $H L X$ gene that has been previously implicated in the pathogenesis of asthma. Our data suggest that differences in DNA methylation associated with childhood asthma which persists into early adulthood are distinct from those associated with childhood asthma which remits before early adulthood.

\section{Methods}

\section{Study cohort}

Participants were recruited from the Environmental Risk (E-Risk) longitudinal twin study, which tracks the development of a birth cohort of 1116 British twin pairs $(n=$ 2232 individuals). The sample was drawn from a larger birth register of twins born in England and Wales in 1994-1995 [59]. Full details about the sample are reported elsewhere [60]. The sample includes $55 \% \mathrm{MZ}$ twin pairs. Sex is evenly distributed within zygosity (49 \% male). The sample was originally assessed when the twins were aged 5, and follow-up home visits took place when the children were aged 7 (98\% participation), 10 (96\% participation), 12 (96\% participation) and 18 years (93\% participation). The Joint South London and Maudsley and the Institute of Psychiatry Research Ethics Committee approved each phase of the study. Prior to age 18, parents gave informed consent and children gave assent; at age 18, the participants themselves gave informed consent.

\section{Measures}

At ages 5 and 10, information was collected from mothers about each child's asthma using an event history calendar for recording children's history of chronic health conditions. Methodological studies document that event history calendars improve accuracy of health information over conventional questionnaire instruments $[48,49]$. A sub-sample of 56 Caucasian families (112 children, 56 twin pairs) was used for this study, comprising families who (a) had MZ twins, and (b) were discordant for asthma at age 10 (37 twin pairs) or (c) both twins did not have asthma (19 twin pairs). All MZ twins were Caucasian and born in the UK. Buccal cell samples were obtained from children during home visits at ages 5 and 10 (see Additional file 2: Table S7 for further details). Genomic DNA was extracted from buccal cells using a standard procedure [61].

When the children were 18 years old, asthmatic symptoms were further assessed in a private individual interview conducted by trained professionals. Three questions were taken from the European Community Respiratory Health Survey (ECRHS) II screening questionnaire (www.ecrhs.org) [51] related to asthma ("Have you been woken by an attack of shortness of breath at any time in the last 12 months?", "Have you had an attack of asthma in the last 12 months?", "Are you currently taking any medicine (including inhalers, aerosols or tablets) for asthma?"). A dichotomous variable representing children who reported no to all three questions and those who reported at least one definite asthma symptom was created. Follow-up phenotypic information was available for 36/37 discordant twin pairs at age 18. Thirteen MZ twin pairs discordant at age 10 remained discordant for asthma at age 18. Twenty MZ twin pairs discordant at age 10 became concordant unaffected at age 18 , and three $\mathrm{MZ}$ twin pairs became concordant affected at age 18 .

\section{Methylomic profiling}

Genomic DNA (500 ng) was treated with sodium bisulfite using the EZ-96 DNA Methylation Kit (Zymo Research, CA, USA) following the manufacturers' protocol. DNA methylation was quantified using the Infinium HumanMethylation450 BeadChip array (Illumina, Inc., San Diego, CA) as previously described [24]. Each twin pair was processed together on the same array to avoid batch effects. Genome Studio software (Illumina, Inc.) was used to extract signal intensities for each probe and perform initial quality control. Further quality control checks, quantile normalization and separate background adjustment of methylated and unmethylated intensities of type I and II 
probes were employed using the wateRmelon package in $\mathrm{R}$ (available from the bioconductor repository www.bioconductor.org) [24]. Samples with $5 \%$ of sites with a detection $P$ value $>.05$ or a bead count $<3$ in $5 \%$ of samples were removed from the analysis. Non-specific probes and probes on the $\mathrm{X}$ and $\mathrm{Y}$ chromosomes were removed [62, 63]. The final analyses included 391,554 probes and included 31 asthma-discordant MZ pairs (62 individual samples) at age 5, $37 \mathrm{MZ}$ pairs (74 individual samples) at age 10, and $19 \mathrm{MZ}$ (38 individual samples) age-10 concordant unaffected pairs. Polymorphic single nucleotide polymorphism control probes $(n=65)$ located on the array were used to confirm monozygosity for all twin pairs included in the final analysis.

\section{Data analyses}

All statistical analyses were performed using $\mathrm{R}$ statistical package (version 3.1.1). Our primary analyses employed a paired $t$ test to identify DMPs between affected twins (children who were reported as having a history of asthma) and unaffected (children who had no reported history of asthma) twin children using DNA collected at age 10. Next, we identified a persistent-asthma subgroup (13 MZ twin pairs) of asthma-discordant MZ twins at age 10 who remained discordant for asthma at age 18. A paired $t$ test was employed to identify DMPs between twins discordant (at both ages 10 and 18) for asthma using DNA collected at age 10. Probes were ranked according to $P$ value. Analyses were repeated for buccal samples collected at age 5 . The Beta value $(\beta)$ is a ratio between methylated probe intensity and total probe intensities (sum of methylated and unmethylated probe intensities) and ranges from 0 to 1 . Within the persistent-asthma sub-group, intra-individual changes in DNA methylation from ages 5 to 10 were calculated (longitudinal $\Delta \beta$ ) and the difference in longitudinal $\Delta \beta$ between persistent-asthma-affected twins and their unaffected co-twin was examined using a paired $t$ test. An empirical $P$ value was calculated for top-ranked DMPs $(P<0.0001)$ in both the asthma-discordant $(n=37$ twin pairs) and the persistent-asthma sub-group ( $n=13$ twin pairs) by first randomly assigning twin status (affected/unaffected) and performing a paired $t$ test. This was repeated for up to 10,000 permutations. An empirical $P$ value was calculated by dividing the number of permutations which are at least as significant as the true result $(P<0.0001)$ by the number of permutations performed.

The specificity of our persistent-asthma-associated DMPs was determined by examining within-twin DNA methylation differences at these loci in (i) an asthmaremission sub-group (twins discordant for asthma at age 10 but the affected twin had remitted at 18, $n=20$ twin pairs) and (ii) concordant unaffected control MZ twins, with no history of asthma in either twin ( $n=19$ twin pairs). For the asthma-remission sub-group, the average within-twin beta difference $(\Delta \beta)$ was calculated, at these loci, by taking the average within-twin beta difference (beta value of asthma-affected twin (age 10) - beta value of unaffected co-twin (age 10)). For the concordant unaffected control MZ twins, the average within-twin beta difference, at these loci, was calculated using permutation testing $(n=1000)$. Briefly, concordant unaffected twin pairs were randomly assigned a dichotomous variable (0 (twin 1) or 1 (twin 2)) and the within-twin beta difference (beta value of twin 1 - beta value of twin 2) was calculated for each twin pair at each probe. Next, the average within-twin beta difference (within-twin $\Delta \beta$ ) was calculated across all twin pairs at each probe, and this was repeated 1000 times. The average within-twin $\Delta \beta$ was calculated by taking the average of the permutated within-twin $\Delta \beta$ values obtained at each DMP of interest. The average within-twin $\Delta \beta$ was then compared to (i) the average within-twin $\Delta \beta$ calculated from the persistent-asthma-discordant MZ twin pairs and (ii) the average within-twin $\Delta \beta$ calculated from the asthmaremission group at each probe of interest using a one-way analysis of variance (ANOVA). Post hoc pairwise comparisons (pairwise $t$ test) were performed to identify which groups were significantly different from each other.

\section{Gene ontology term enrichment analysis}

Gene ontology (GO) term enrichment analysis was performed on genes annotated (Illumina UCSC gene annotation) to age-10 DMPs, age-10 persistent-asthma DMPs and longitudinal DMPs (nominal $P<0.001$ ), respectively, using the $\mathrm{R}$ package GOseqv1.18.1 (downloaded from Bioconductor [64]). GOseq can be used to correct for the number of Illumina $450 \mathrm{~K}$ probes in each gene during GO term enrichment analysis. The number of probes per gene was calculated in our final dataset to create a probability weighting function, which was then used in the GO term enrichment analysis.

\section{Additional files}

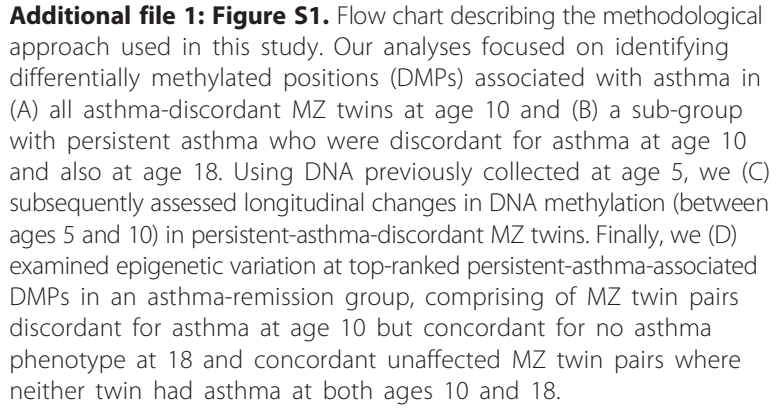

Additional file 1: Figure S1. Flow chart describing the methodological approach used in this study. Our analyses focused on identifying differentially methylated positions (DMPs) associated with asthma in (A) all asthma-discordant MZ twins at age 10 and (B) a sub-group with persistent asthma who were discordant for asthma at age 10 and also at age 18. Using DNA previously collected at age 5, we (C) subsequently assessed longitudinal changes in DNA methylation (between ages 5 and 10) in persistent-asthma-discordant MZ twins. Finally, we (D) examined epigenetic variation at top-ranked persistent-asthma-associated DMPs in an asthma-remission group, comprising of MZ twin pairs discordant for asthma at age 10 but concordant for no asthma phenotype at 18 and concordant unaffected $M Z$ twin pairs where neither twin had asthma at both ages 10 and 18 . 
Additional file 2: Tables S1-S7. Table S1. The top-ranked DMPs $(P<0.001)$ in discordant MZ twin pairs at age 10. Table S2. Gene ontology enrichment analysis for age-10 asthma-associated DMPs.

Table S3. The top-ranked DMPs at age 10 in persistent-asthma-discordant MZ twins (between 10 and 18 years). Table S4. Gene ontology enrichment analysis for persistent-asthma age-10 DMPs. Table S5. The top-ranked CpG sites which show changes in DNA methylation levels between 5 and 10 years of age in the asthma-discordant MZ twins. Table S6. Gene ontology enrichment analysis of longitudinal DMPs between 5 and 10 years of age. Table S7. Monozygotic twin group details.

\section{Competing interests}

The authors declare that they have no competing interests.

\section{Authors' contributions}

TMM performed and supervised the laboratory work, conducted the data processing and statistical analysis and drafted the manuscript. JB and RM contributed to the DNA methylation experiments. CCW and EH contributed to the data processing and statistical analysis. AA managed the phenotypic data collation for the E-Risk cohort. HLF contributed the methylation data for the control twins for this study and helped draft the manuscript. JM, AC, TEM and LA secured the funding for the study, designed the study, recruited and maintained the cohort, collected the measures of asthma and helped draft the manuscript. All authors participated in the revision of the manuscript, and all authors read and approved the final manuscript.

\section{Acknowledgements}

We are grateful to the study mothers and fathers, the twins, and the twins' teachers for their participation. We thank the members of the E-Risk team for their contribution to this study. The E-Risk Study was funded by a Medical Research Council (MRC) grant (G1002190) and a National Institute of Child Health and Development (NICHD) grant (HD077482), and this work was funded by the American Asthma Foundation and an MRC Centenary Award to HLF (G9817803-E02/1).

\section{Author details}

${ }^{1}$ University of Exeter Medical School, University of Exeter, Exeter, UK. ${ }^{2}$ MRC Social, Genetic \& Developmental Psychiatry Centre, Institute of Psychiatry, Psychology \& Neuroscience, King's College London, London, UK. ${ }^{3}$ Department of Psychology and Neuroscience, Duke University, Durham, NC, USA. ${ }^{4}$ Department of Psychiatry and Behavioral Sciences, Duke University Medical School, Durham, NC, USA.

Received: 27 July 2015 Accepted: 11 December 2015

Published online: 18 December 2015

\section{References}

1. Ober C, Yao TC. The genetics of asthma and allergic disease: a 21st century perspective. Immunol Rev. 2011;242(1):10-30. doi:10.1111/j.1600-065X.2011. 01029.x.

2. WHO Media Center. Asthma fact sheet $N^{\circ} 307$. Updated November 2014; http://www.who.int/mediacentre/factsheets/fs307/en/.

3. Sears MR, Greene JM, Willan AR, Wiecek EM, Taylor DR, Flannery EM, et al. A longitudinal, population-based, cohort study of childhood asthma followed to adulthood. N Engl J Med. 2003;349(15):1414-22. doi:10.1056/NEJMoa022363.

4. Strachan DP, Butland BK, Anderson HR. Incidence and prognosis of asthma and wheezing illness from early childhood to age 33 in a national British cohort. BMJ. 1996;312(7040):1195-9.

5. Agache I, Akdis C, Jutel M, Virchow JC. Untangling asthma phenotypes and endotypes. Allergy. 2012;67(7):835-46. doi:10.1111/j.1398-9995.2012.02832.x.

6. Bonfield TL, Ross KR. Asthma heterogeneity and therapeutic options from the clinic to the bench. Curr Opin Allergy Clin Immunol. 2012;12(1):60-7. doi:10.1097/ACl.0b013e32834edb5b.

7. Belsky DW, Sears MR, Hancox RJ, Harrington H, Houts R, Moffitt TE, et al. Polygenic risk and the development and course of asthma: an analysis of data from a four-decade longitudinal study. Lancet Respir Med. 2013;1(6): 453-61. doi:10.1016/S2213-2600(13)70101-2.

8. Thomsen SF, van der Sluis S, Kyvik KO, Skytthe A, Backer V. Estimates of asthma heritability in a large twin sample. Clin Exp Allergy. 2010;40(7): 1054-61. doi:10.1111/j.1365-2222.2010.03525.x.
9. Duffy DL, Martin NG, Battistutta D, Hopper JL, Mathews JD. Genetics of asthma and hay fever in Australian twins. Am Rev Respir Dis. 1990;142(6 Pt 1):1351-8. doi:10.1164/ajrccm/142.6_Pt_1.1351.

10. Nieminen MM, Kaprio J, Koskenvuo M. A population-based study of bronchial asthma in adult twin pairs. Chest. 1991;100(1):70-5.

11. Moffatt MF, Gut IG, Demenais F, Strachan DP, Bouzigon E, Heath S, et al. A large-scale, consortium-based genomewide association study of asthma. N Engl J Med. 2010;363(13):1211-21. doi:10.1056/NEJMoa0906312.

12. Torgerson DG, Ampleford EJ, Chiu GY, Gauderman WJ, Gignoux CR, Graves PE, et al. Meta-analysis of genome-wide association studies of asthma in ethnically diverse North American populations. Nat Genet. 2011;43(9):887-92. doi:10.1038/ng.888.

13. Tariq SM, Hakim EA, Matthews SM, Arshad SH. Influence of smoking on asthmatic symptoms and allergen sensitisation in early childhood. Postgrad Med J. 2000;76(901):694-9.

14. Stein RT, Sherrill D, Morgan WJ, Holberg CJ, Halonen M, Taussig LM, et al. Respiratory syncytial virus in early life and risk of wheeze and allergy by age 13 years. Lancet. 1999;354(9178):541-5. doi:10.1016/S01406736(98)10321-5.

15. Bisgaard H, Hermansen MN, Buchvald F, Loland L, Halkjaer LB, Bonnelykke K, et al. Childhood asthma after bacterial colonization of the airway in neonates. N Engl J Med. 2007;357(15):1487-95. doi:10.1056/NEJMoa052632.

16. Murphy TM, Mill J. Epigenetics in health and disease: heralding the EWAS era. Lancet. 2014;383(9933):1952-4. doi:10.1016/S0140-6736(14)60269-5.

17. Zhang H, Tong X, Holloway JW, Rezwan Fl, Lockett GA, Patil V, et al. The interplay of DNA methylation over time with Th2 pathway genetic variants on asthma risk and temporal asthma transition. Clin Epigenetics. 2014;6(1):8. doi:10.1186/1868-7083-6-8

18. Runyon RS, Cachola LM, Rajeshuni N, Hunter T, Garcia M, Ahn R, et al. Asthma discordance in twins is linked to epigenetic modifications of $T$ cells. PLoS One. 2012;7(11):e48796. doi:10.1371/journal.pone.0048796.

19. Lovinsky-Desir S, Ridder R, Torrone D, Maher C, Narula S, Scheuerman M, et al. DNA methylation of the allergy regulatory gene interferon gamma varies by age, sex, and tissue type in asthmatics. Clin Epigenetics. 2014;6(1):9. doi: 10.1186/1868-7083-6-9.

20. Mikhaylova L, Zhang Y, Kobzik L, Fedulov AV. Link between epigenomic alterations and genome-wide aberrant transcriptional response to allergen in dendritic cells conveying maternal asthma risk. PLoS One. 2013;8(8): e70387. doi:10.1371/journal.pone.0070387.

21. Yang IV, Pedersen BS, Liu A, O'Connor GT, Teach SJ, Kattan M, et al. DNA methylation and childhood asthma in the inner city. J Allergy Clin Immunol. 2015;136(1):69-80. doi:10.1016/j.jaci.2015.01.025.

22. Liang L, Willis-Owen SA, Laprise C, Wong KC, Davies GA, Hudson TJ, et al. An epigenome-wide association study of total serum immunoglobulin $E$ concentration. Nature. 2015. doi:10.1038/nature14125.

23. Mill J, Heijmans BT. From promises to practical strategies in epigenetic epidemiology. Nat Rev Genet. 2013;14(8):585-94. doi:10.1038/nrg3405.

24. Pidsley R, CC YW, Volta M, Lunnon K, Mill J, Schalkwyk LC. A data-driven approach to preprocessing Illumina 450K methylation array data. BMC Genomics. 2013;14:293. doi:10.1186/1471-2164-14-293.

25. Pedersen S. Preschool asthma—not so easy to diagnose. Prim Care Respir J. 2007;16(1):4-6. doi:10.3132/pcrj.2007.00011.

26. Doherty $\mathrm{G}$, Bush A. Diagnosing respiratory problems in young children. Practitioner. 2007;251(1697):20. 2-5.

27. Lu LQ, Liao W. Screening and functional pathway analysis of genes associated with pediatric allergic asthma using a DNA microarray. Mol Med Rep. 2015 doi:10.3892/mmr.2015.3277

28. Danahay H, Atherton H, Jones G, Bridges RJ, Poll CT. Interleukin-13 induces a hypersecretory ion transport phenotype in human bronchial epithelial cells. Am J Physiol Lung Cell Mol Physiol. 2002;282(2):L226-36. doi:10.1152/ajplung.00311.2001.

29. Suttner K, Ruoss I, Rosenstiel P, Depner M, Pinto LA, Schedel M, et al. HLX gene variants influence the development of childhood asthma. J Allergy Clin Immunol. 2009;123(1):82-8. doi:10.1016/j.jaci.2008.09.047. e6.

30. Suttner K, Rosenstiel P, Depner M, Schedel M, Pinto LA, Ruether A, et al. TBX21 gene variants increase childhood asthma risk in combination with HLX1 variants. J Allergy Clin Immunol. 2009;123(5):1062-8. doi:10.1016/j.jaci. 2009.02.025. 8 e1-8.

31. Casaca VI, Illi S, Suttner K, Schleich I, Ballenberger N, Klucker E, et al. TBX21 and HLX1 polymorphisms influence cytokine secretion at birth. PLoS One. 2012;7(1):e31069. doi:10.1371/journal.pone.0031069. 
32. Malek TR, Castro I. Interleukin-2 receptor signaling: at the interface between tolerance and immunity. Immunity. 2010;33(2):153-65. doi:10.1016/j.immuni. 2010.08.004

33. Gonzalez-Navajas JM, Lee J, David M, Raz E. Immunomodulatory functions of type I interferons. Nat Rev Immunol. 2012;12(2):125-35. doi:10.1038/nri3133.

34. Boonpiyathad S, Pornsuriyasak P, Buranapraditkun S, Klaewsongkram J. Interleukin-2 levels in exhaled breath condensates, asthma severity, and asthma control in nonallergic asthma. Allergy Asthma Proc. 2013;34(5):e35-41. doi:10.2500/aap.2013.34.3680.

35. Patel DA, You Y, Huang G, Byers DE, Kim HJ, Agapov E, et al. Interferon response and respiratory virus control are preserved in bronchial epithelial cells in asthma. J Allergy Clin Immunol. 2014;134(6):1402-12. doi:10.1016/j.jaci.2014.07.013. e7.

36. Mullen AC, Hutchins AS, High FA, Lee HW, Sykes KJ, Chodosh LA, et al. HIX is induced by and genetically interacts with T-bet to promote heritable $T(H) 1$ gene induction. Nat Immunol. 2002;3(7):652-8. doi:10.1038/ni807.

37. Isobe M, Huebner K, Maddon PJ, Littman DR, Axel R, Croce CM. The gene encoding the T-cell surface protein T4 is located on human chromosome 12. Proc Natl Acad Sci U S A. 1986;83(12):4399-402.

38. Kon OM, Kay AB. T cells and chronic asthma. Int Arch Allergy Immunol. 1999:118(2-4):133-5. doi:24049.

39. Chapoval Al, Ni J, Lau JS, Wilcox RA, Flies DB, Liu D, et al. B7-H3: a costimulatory molecule for T cell activation and IFN-gamma production. Nat Immunol. 2001; 2(3):269-74. doi:10.1038/85339.

40. Damera G, Xia B, Sachdev GP. IL-4 induced MUC4 enhancement in respiratory epithelial cells in vitro is mediated through JAK-3 selective signaling. Respir Res. 2006;7:39. doi:10.1186/1465-9921-7-39.

41. Ordonez $\mathrm{CL}$, Khashayar R, Wong HH, Ferrando R, Wu R, Hyde DM, et al. Mild and moderate asthma is associated with airway goblet cell hyperplasia and abnormalities in mucin gene expression. Am J Respir Crit Care Med. 2001; 163(2):517-23. doi:10.1164/ajrccm.163.2.2004039.

42. Dempster EL, Pidsley R, Schalkwyk LC, Owens S, Georgiades A, Kane F, et al. Disease-associated epigenetic changes in monozygotic twins discordant for schizophrenia and bipolar disorder. Hum Mol Genet. 2011;20(24):4786-96. doi:10.1093/hmg/ddr416

43. Wong CC, Meaburn EL, Ronald A, Price TS, Jeffries AR, Schalkwyk LC, et al. Methylomic analysis of monozygotic twins discordant for autism spectrum disorder and related behavioural traits. Mol Psychiatry. 2014;19(4):495-503. doi:10.1038/mp.2013.41.

44. McDermott E, Ryan EJ, Tosetto M, Gibson D, Burrage J, Keegan D, et al. DNA methylation profiling in inflammatory bowel disease provides new insights into disease pathogenesis. J Crohns Colitis. 2015. doi:10.1093/ecco-jcc/jjv176.

45. He N, Liu M, Hsu J, Xue Y, Chou S, Burlingame A, et al. HIV-1 Tat and host AFF4 recruit two transcription elongation factors into a bifunctional complex for coordinated activation of HIV-1 transcription. Mol Cell. 2010; 38(3):428-38. doi:10.1016/j.molcel.2010.04.013.

46. Roy MG, Livraghi-Butrico A, Fletcher AA, McElwee MM, Evans SE, Boerner RM, et al. Muc5b is required for airway defence. Nature. 2014; 505(7483):412-6. doi:10.1038/nature12807.

47. Kariyawasam HH, Pegorier S, Barkans J, Xanthou G, Aizen M, Ying S, et al. Activin and transforming growth factor-beta signaling pathways are activated after allergen challenge in mild asthma. J Allergy Clin Immunol. 2009;124(3):454-62. doi:10.1016/j.jaci.2009.06.022.

48. Belli RSL, Andreski P, Agawal S. Methodological comparisons between CATI event history calendar and standardized conventional questionnaire instruments. Public Opin Q. 2007;71(4):603-22.

49. Caspi AMT, Thornton A, Freedman D, Amell J, Harrington H, Smeijers J, et al. The life history calendar: a research and clinical assessment method for collecting retrospective event-history data. Int J Method Psych. 1996;6(2):101-14.

50. Kelleher I, Harley M, Murtagh A, Cannon M. Are screening instruments valid for psychotic-like experiences? A validation study of screening questions for psychotic-like experiences using in-depth clinical interview. Schizophr Bull. 2011;37(2):362-9. doi:10.1093/schbul/sbp057.

51. European Community Respiratory Health Survey IISC. The European Community Respiratory Health Survey II. Eur Respir J. 2002;20(5):1071-9.

52. Odgers CL, Donley S, Caspi A, Bates CJ, Moffitt TE. Living alongside more affluent neighbors predicts greater involvement in antisocial behavior among low-income boys. J Child Psychol Psychiatry. 2015. doi:10.1111/jcpp.12380.
53. Rakyan VK, Down TA, Balding DJ, Beck S. Epigenome-wide association studies for common human diseases. Nat Rev Genet. 2011;12(8):529-41. doi:10.1038/nrg3000

54. Wilhelm-Benartzi CS, Koestler DC, Karagas MR, Flanagan JM, Christensen $B C$, Kelsey KT, et al. Review of processing and analysis methods for DNA methylation array data. Br J Cancer. 2013;109(6):1394-402. doi:10. 1038/bjc.2013.496

55. Dempster EL, Wong CC, Lester KJ, Burrage J, Gregory AM, Mill J, et al. Genome-wide methylomic analysis of monozygotic twins discordant for adolescent depression. Biol Psychiatry. 2014;76(12):977-83. doi:10.1016/j. biopsych.2014.04.013

56. Lunnon K, Smith R, Hannon E, De Jager PL, Srivastava G, Volta M, et al. Methylomic profiling implicates cortical deregulation of ANK1 in Alzheimer's disease. Nat Neurosci. 2014;17(9):1164-70. doi:10.1038/nn.3782.

57. Roessler J, Ammerpohl O, Gutwein J, Hasemeier B, Anwar SL, Kreipe H, et al. Quantitative cross-validation and content analysis of the $450 \mathrm{k}$ DNA methylation array from Illumina, Inc. BMC Res Notes. 2012;5:210. doi:10.1186/1756-0500-5-210.

58. Gordon L, Joo JE, Powell JE, Ollikainen M, Novakovic B, Li X, et al. Neonatal DNA methylation profile in human twins is specified by a complex interplay between intrauterine environmental and genetic factors, subject to tissue-specific influence. Genome Res. 2012;22(8): 1395-406. doi:10.1101/gr.136598.111.

59. Trouton A, Spinath FM, Plomin R. Twins early development study (TEDS): a multivariate, longitudinal genetic investigation of language, cognition and behavior problems in childhood. Twin Res. 2002;5(5):444-8. doi:10.1375/136905202320906255

60. Moffitt TE, Team ERS. Teen-aged mothers in contemporary Britain. J Child Psychol Psychiatry. 2002;43(6):727-42.

61. Freeman B, Smith N, Curtis C, Huckett L, Mill J, Craig IW. DNA from buccal swabs recruited by mail: evaluation of storage effects on long-term stability and suitability for multiplex polymerase chain reaction genotyping. Behav Genet. 2003;33(1):67-72.

62. Price ME, Cotton AM, Lam LL, Farre P, Emberly E, Brown CJ, et al. Additional annotation enhances potential for biologically-relevant analysis of the Illumina Infinium HumanMethylation450 BeadChip array. Epigenetics Chromatin. 2013;6(1):4. doi:10.1186/1756-8935-6-4.

63. Chen YA, Lemire M, Choufani S, Butcher DT, Grafodatskaya D, Zanke BW, et al. Discovery of cross-reactive probes and polymorphic CpGs in the Illumina Infinium HumanMethylation450 microarray. Epigenetics. 2013;8(2):203-9. doi:10.4161/epi.23470.

64. Young MD, Wakefield MJ, Smyth GK, Oshlack A. Gene ontology analysis for RNA-seq: accounting for selection bias. Genome Biol. 2010;11(2):R14. doi:10.1186/gb-2010-11-2-r14.

\section{Submit your next manuscript to BioMed Central and we will help you at every step:}

- We accept pre-submission inquiries

- Our selector tool helps you to find the most relevant journal

- We provide round the clock customer support

- Convenient online submission

- Thorough peer review

- Inclusion in PubMed and all major indexing services

- Maximum visibility for your research

Submit your manuscript at www.biomedcentral.com/submit 